\title{
A Rare Overgrowth Disorder: Sotos Syndrome
}

\author{
Burcin Sanlidag, ${ }^{1,}$ Ceyhun Dalkan, ${ }^{1}$ Nilufer Gali, ${ }^{1}$ Ozlem Sahaloglu, ${ }^{1}$ Nerin Bahceciler Onder, ${ }^{1}$ and Eray \\ $\operatorname{Dirik}^{1}$ \\ ${ }^{1}$ Department of Pediatrics, Near East University, Nicosia, Cyprus \\ Corresponding author: Burcin Sanlidag, Department of Pediatrics, Near East University, Nicosia, Cyprus. Tel: +90-3126751000, E-mail: burcinsanlidag@yahoo.com
}

Received 2016 April 22; Revised 2016 August 10; Accepted 2016 September 12.

Keywords: Sotos Syndrome, Rash, NSD 1 Mutation

\section{Dear Editor,}

Sotos Syndrome (SS) is a rare childhood overgrowth condition that was first described in 1964 by Sotos et al. (1). It is an autosomal dominant syndrome with a birth prevalence of 7/100.000 (2). Sotos Syndrome can be characterized by pre and postnatal accelerated growth with advanced bone age, developmental delay, distinctive facial features and macrocephaly (3). The diagnosis of the disease has always been based on clinical criteria, until more recently when genotyping has become an additional assessment tool for the diagnosis of the condition.

Specific gene mutations and deletions associated with the nuclear receptor binding SET Domain protein 1 (NSD1) gene that is located on chromosome $5 q 35$ and has been defined. The NSD 1 gene was identified to have a role in growth and brain development in humans and can assist with the diagnosis of the condition $(4,5)$.

Although it is a well-defined condition phenotypically, it is difficult to diagnose particularly for inexperienced clinicians. Establishing an accurate diagnosis at an early age is particularly important for long-term follow up check-ups because of the developmental delay, cardiac pathologies, scoliosis and increased risk of malignancies.

The patient was the first child of non-consanguineous parents. There was no family history of a similar disease and the child's sibling was healthy. The patient was born term and was large for gestational age. She was admitted to the Department of Allergy with complaints of a rash at the age of five and had mild mental retardation and a low school performance record. On physical examination, her weight was $27.600 \mathrm{gr}$ ( $>$ 97th percentile), height 124.5 ( $>$ 97th percentile) and head circumference $55 \mathrm{~cm}$ (> 97th percentile). The patient had a hyperpigmented rash, which appeared prominent at the site of the thorax and arms. The patient presented particular characteristics, which included a long face, high forehead, high frontal hairline, prominent jaw, malocclusion of teeth, down-slanting palpebral fissures and scoliosis, as presented in Figure 1 in addition to a 2/6 systolic murmur at the pulmonary focus. In addition, hearing test, eye examinations and abdominal ultrasonography were all normal. Her bone age was advanced being appropriate for 10 years of age. Echocardiography examination revealed secundum ASD and a bicuspid aortic valve. Magnetic resonance imaging (MRI) of the brain was normal. Histopathological evaluation of the skin biopsy material revealed minimal spongiosis in epidermis, covered with mild hyperkeratosis in addition to lymphocytic infiltration around vascular structures in papillary dermis. All routine laboratory test results including allergy and vasculitis workup were within the normal range. Taken together the patient's clinical features were suggestive of SS and further genetic analyses revealed NSD1:c.5885T > C pathogenic variant heterozygote mutation. The skin lesions' appearance did not change or resolve during the three-year follow up.

In general, patients with SS have non-progressive neurologic dysfunction, $97 \%$ of patients have learning disabilities, 50\% have seizures, and 30\% have behavioral problems, social isolation issues and psychiatric disorders (6). The vast majority of individuals with Sotos syndrome had intellectual disability or borderline intellectual functioning like our patient (7). No seizures or social isolation issues were detected in our patient, while learning disability was identified.

In another case, described with the same NSD1c, 5885T $>\mathrm{C}$ mutation overgrowth, advanced bone age and down slanting palpebral fissures were present similar to our patient, while head circumference and mental status were normal in that patient unlike our patient (8). More reports are needed for the definition of various geneticphenotypic correlations.

Although the histopathology of the hyperpigmented skin lesions revealed perivascular lymphocytic infiltration, absence of vessel wall destruction, fibrin deposition and hemorrhage in addition to the negative clinical and laboratory elements suggestive of the diagnosis of lym-

Copyright (C) 2016, Growth \& Development Research Center. This is an open-access article distributed under the terms of the Creative Commons Attribution-NonCommercial 4.0 International License (http://creativecommons.org/licenses/by-nc/4.0/) which permits copy and redistribute the material just in noncommercial usages, provided the original work is properly cited. 


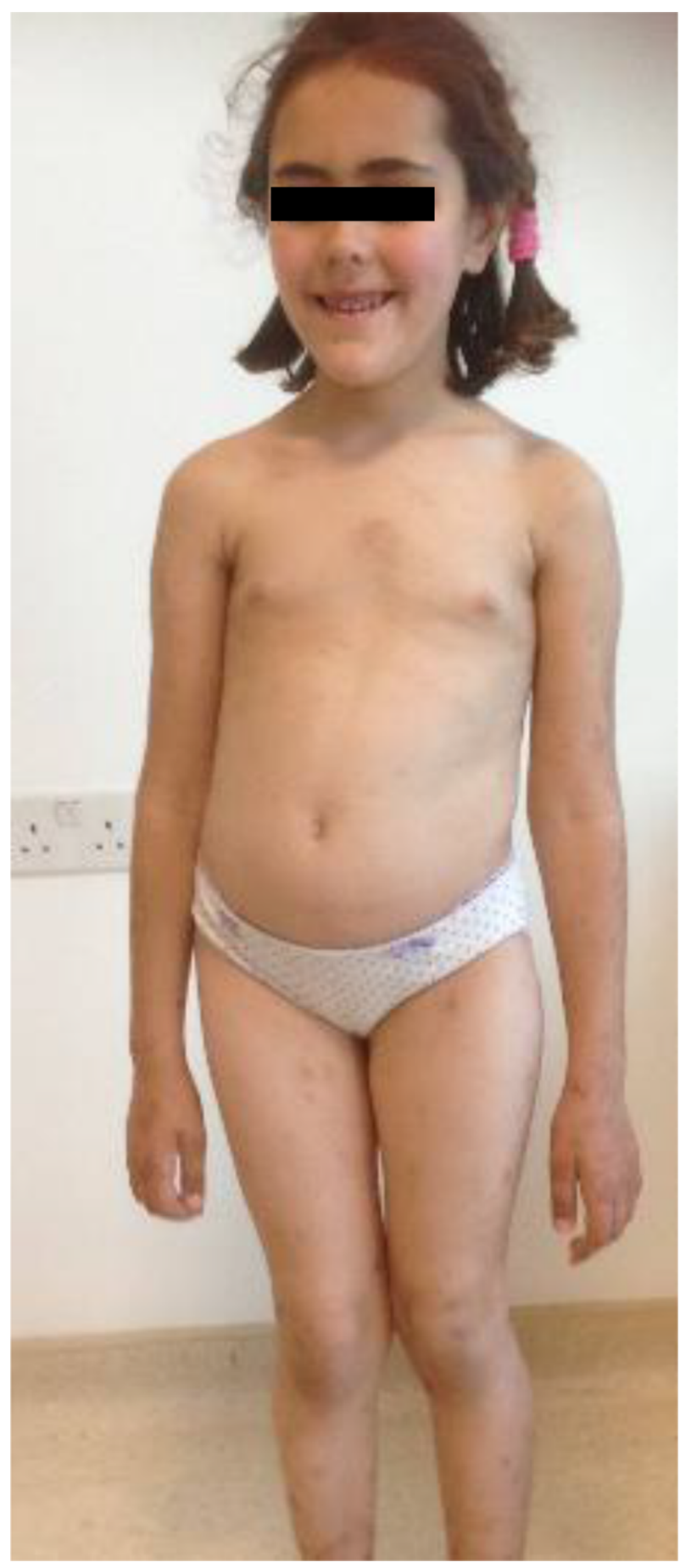

Figure 1. Dysmorphic Facial Features; Long Face, High Forehead, High Frontal Hairline, Prominent Jaw, Down-Slanting Palpebral Fissures and Rash Were Noted on Physical Examination phocytic vasculitis moved us away from vasculitis (9). To date no SS case with permanent hyper-pigmented skin lesions has been described.

Clinical diagnosis confirmed by genetic evaluation is particularly important especially for familial cases, for genetic counseling and prenatal diagnosis.

\section{References}

1. Sotos JF, Dodge PR, Muirhead D, Crawford JD, Talbot NB. Cerebral Gigantism in Childhood. A Syndrome of Excessively Rapid Growth and Acromegalic Features and a Nonprogressive Neurologic Disorder. N Engl J Med. 1964;271:109-16. doi: 10.1056/NEJM196407162710301. [PubMed: 14148233].

2. Rath A, Wakap SN, Demarest S, Lanneau V. Prevalence of rare diseases: Bibliographic data. Orphanet Report Series. 2012;1:26.

3. Cole TR, Hughes HE. Sotos syndrome: a study of the diagnostic criteria and natural history. J Med Genet. 1994;31(1):20-32. [PubMed: 7512144].

4. Kurotaki N, Imaizumi K, Harada N, Masuno M, Kondoh T, Nagai T, et al. Haploinsufficiency of NSD1 causes Sotos syndrome. Nat Genet. 2002;30(4):365-6. doi:10.1038/ng863. [PubMed: 11896389].

5. Kilic E, Utine GE, Boduroglu K. A case of Sotos syndrome with $5 \mathrm{q} 35 \mathrm{mi}-$ crodeletion and novel clinical findings. Turk J Pediatr. 2013;55(2):207-9. [PubMed: 24192683].

6. Tatton-Brown K, Douglas J, Coleman K, Baujat G, Cole TR, Das S, et al Genotype-phenotype associations in Sotos syndrome: an analysis of 266 individuals with NSD1 aberrations. Am J Hum Genet. 2005;77(2):193204. doi: 10.1086/432082. [PubMed: 15942875].

7. Lane C, Milne E, Freeth M. Cognition and Behaviour in Sotos Syndrome: A Systematic Review. PLoS One. 2016;11(2):0149189. doi: 10.1371/journal.pone.0149189. [PubMed: 26872390].

8. de Boer L, Kant SG, Karperien M, van Beers L, Tjon J, Vink GR, et al Genotype-phenotype correlation in patients suspected of having Sotos syndrome. Horm Res. 2004;62(4):197-207. doi: 10.1159/000081063. [PubMed: 15452385].

9. Kossard S. Defining lymphocytic vasculitis. Australas J Dermatol. 2000;41(3):149-55. [PubMed:10954985]. 